\title{
ANALISIS PENGELOLAAN LIMBAH MEDIS PADAT UNTUK MEWUJUDKAN KONSEP GREEN HOSPITAL DI RSUP DR. M. DJAMIL PADANG
}

\author{
Pratiwi Herman $^{1^{*}}$, Nopriadi $^{* 2}$ \\ ${ }^{1}$ Fakultas Kesehatan Masyarakat Universitas Andalas, Padang \\ ${ }^{2}$ Fakultas Keperawatan Universitas Riau \\ *Koresponden E-mail: nopriadi_dhs@yahoo.com
}

\begin{abstract}
A hospital can apply Green Hospital concept in order to reduce even hospital environment and global environment pollution. The amount of patients at Dr. M. Djamil Padang hospital is 250.000-350.000 every year which make hospital generates medical waste $\pm 400 \mathrm{~kg}$ /day on giving health service. Therefore, Dr. M. Djamil Padang hospital should have integrated and sustainable solid medical waste management. Purpose of this research is to analyze the management of solid medical waste management at Dr. M. Djamil Hospital on creating Green Hospital concept. Study of this research is qualitative study. This research was conducted on March-June 2018. There are 9 informants which determined by purposive sampling technique. Data is collected with in-depth interview, observation, and document reviewing. Data are analyzed by data reduction, presentation of data, and conclusion. Data validity were used source triangulation and method triangulation. Input component: hospital has writtern procedure in solid medical waste management, cost and staff regarding solid medical waste management is sufficient, all facilities is appropriate except for temporary storage for medical waste. Process component: waste segregation is carried out according to its character. Waste transportation to temporary storage uses trolly, howeverit doesn't use special lane. Hospital cooperates with third party on exterminating medical waste with incinerator. Output component: overall, implementation of solid medical waste management at Dr. M. Djamil Hospital Padang has been in accordance with the Indonesian health regulation No. 1204/2004 and hospital has conducted the efforts towards green hospital by doing appropriate solid medical waste management. Referenced to the Indonesian health regulation No. 1204/2004, solid medical waste management at Dr. M. Djamil hospital is carried out properly. But there are still problems found, such as temporary storage is not in accordance with the standard. To achieve Green Hospital, hospital can fix broken facilities and apply waste reduction program.
\end{abstract}

\section{Keywords: Dr. M. Djamil Hospital, Green Hospital, Solid Medical Waste}

Sebagai sarana umum rumah sakit mengkonsumsi sumber daya alam dalam kapasitas besar seperti air bersih, listrik, bahan bakar, dan kertas sehingga menghasilkan limbah padat dan cair setiap harinya. Sebuah langkah yang arif dan bijaksana apabila rumah sakit dapat memberikan pelayanan kesehatan terbaik diiringi dengan keikutsertaan dalam upaya melestarikan lingkungan melalui konsep Green Hospital. ( Kemenkes RI, 2016)

Rumah sakit melalui konsep Green Hospital merupakan rumah sakit yang peduli akan lingkungan, karena rumah sakit memiliki dampak yang sangat besar terhadap lingkungan sekitar maupun lingkungan global. Green Hospital berfokus ke Rumah Sakit dengan melihat lingkungan sebagai bagian dari layanan yang berkualitas. Hal ini mencakup lokasi strategis, penggunaan air yang efisien, pengontrolan terhadap polusi energi dan udara, penggunaan bahan-bahan yang ramah lingkungan, penjagaan kualitas dalam ruangan dan penyediaan taman, penyediaan makanan sehat, serta pengurangan limbah. (Azmal dan Kahlor, 2014)

Kementerian Lingkungan Hidup (KLH) Indonesia telah memasukkan rumah sakit ke dalam Program Penilaian Peringkat Kinerja Perusahaan Dalam Pengelolaan Lingkungan Hidup (PROPER) yang dikembangkan oleh KLH sebagai langkah untuk mendukung penerapan program Green Hospital di
Indonesia. Perwujudan Green Hospital di Indonesia juga merupakan target Direktorat Jenderal Bina Upaya Kesehatan bahwa pada tahun 2020 seluruh rumah sakit di Indonesia telah menerapkan konsep Green Hospital. Hal ini didukung dengan adanya program dari Kementerian Kesehatan yang mengadakan lomba Green Hospital setiap tahunnya yang sudah dimulai dari tahun 2016. Berdasarkan program tersebut, Rumah sakit yang telah terakreditasi kelas A dan B diprioritaskan untuk dapat mengikuti lomba Green Hospital, namun tidak menutup kemungkinan bagi rumah sakit kelas $\mathrm{C}$ dan $\mathrm{D}$ untuk menerapkan konsep Green Hospital. (Kemenkes RI, 2014) (Risnawati et al, 2015)

Berdasarkan hasil penelitian Putri (2016) mengenai kesiapan rumah sakit di Kota Malang menuju Green Hospital menunjukkan bahwa kesiapan rata-rata rumah sakit masih ragu-ragu atau belum cukup siap menerapkan Green Hospital di Indonesia. Ketidaksiapan terletak pada kriteria bangunan, kriteria Program Penilaian Peringkat Kinerja Perusahaan (PROPER), dan kriteria pengelolaan sumber daya. (Putri et al, 2016)

Sistem pengelolaan limbah rumah sakit diperlukan dikarenakan kegiatan pelayanan di rumah sakit menghasilkan limbah klinis atau infeksius yang dapat menimbulkan gangguan kesehatan dan pencemaran lingkungan jika tidak ditangani dengan 
baik. Dengan mempertimbangkan risiko yang mungkin terjadi, maka dari itu rumah sakit dipengaruhi oleh beberapa peraturan pemerintah dengan mewajibkan setiap orang memelihara kelestarian fungsi lingkungan hidup serta mencegah dan menanggulangi pencemaran dan perusakan lingkungan hidup. (Kepmenkes RI. 2004)

Rumah Sakit Umum Pusat (RSUP) Dr. M. Djamil Padang merupakan rumah sakit tipe A pendidikan yang terakreditasi Paripurna. Merupakan rumah sakit rujukan di Sumatera Bagian Tengah dengan rata-rata jumlah kunjungan sebanyak 250.000350.000 pasien setiap tahunnya, sehingga dalam pelayanan kesehatan rumah sakit menghasilkan limbah medis padat 400-450 kg setiap harinya. Dengan demikian, pihak rumah sakit harus memiliki sistem pengelolaan limbah medis padat yang berkelanjutan.

Rumah Sakit belum memiliki kebijakan dalam upaya penerapan konsep Green Hospital. Namun demikian, pengelolaan limbah padat di RSUP Dr. M. Djamil Padang secara umum telah mengikuti persyaratan limbah medis padat berdasarkan Keputusan Menteri Kesehatan RI No 1204/Menkes/SK/X/2004 tentang Persyaratan Kesehatan Lingkungan Rumah Sakit.

Dalam pengelolaan limbah medis padat, RSUP Dr. M. Djamil Padang telah menyediakan pewadahan dan pemilahan antara limbah medis dan non medis. Walaupun terkadang masih ditemukan sampah yang tidak sesuai dengan jenisnya. Dalam pengangkutan limbah, rumah sakit belum menyediakan jalur khusus, namun masih melewati lorong rumah sakit. Limbah medis yang telah dikumpulkan kemudian disimpan di TPS khusus limbah medis padat rumah sakit. Kondisi TPS masih belum memenuhi standar, dikarenakan limbah infeksius dan benda tajam masih disimpan di dalam TPS yang sama.

Dalam melakukan pemusnahan akhir limbah, rumah sakit bekerjasama dengan pihak ketiga dikarenakan insinerator milik rumah sakit belum memiliki izin dari Kementerian Lingkungan Hidup sehingga tidak bisa dioperasikan. Transporter limbah medis padat datang untuk mengangkut limbah dua kali seminggu. Sehingga hal tersebut menyebabkan penumpukan limbah medis di TPS.

Berdasarkan permasalahan di atas penulis tertarik untuk melakukan penelitian tentang Analisis Pengelolaan Limbah Medis Padat Di RSUP Dr. M. Djamil Padang Untuk Mewujudkan Konsep Green Hospital.

\section{BAHAN DAN METODE}

Penelitian ini dilakukan di Wilayah Kerja Jenis penelitian ini adalah penelitian dengan pendekatan kualitatif. Penelitian dilakukan di RSUP Dr. M. Djamil Padang Kota Padang, Provinsi Sumatera Barat pada bulan Maret sampai dengan Juni 2018. Informan pada penelitian ini dipilih berdasarkan teknik purposive sampling. Sehubungan dengan tujuan penelitian dalam mengetahui dan menganalisis pengelolaan limbah medis padat maka dipilih informan yang berjumlah 9 orang dengan kriteria pengambilan sampel yaitu dapat dipercaya, paham dengan permasalahan, dan berpengalaman minimal 2 tahun masa kerja di bidang tersebut. Pengumpulan data dilakukan dengan cara memperoleh data primer dan data sekunder. Data primer bersumber dari hasil pengamatan langsung pada objek penelitian dengan menggunakan pedoman observasi dan wawancara mendalam pada sembilan orang informan. Sedangkan untuk data sekunder diperoleh dari telaah dokumen. Analisis data pada penelitian ini dilakukan dengan tahapan redukasi data, penyajian data, penarikan kesimpulan. Setelah itu data divalidasi dengan cara triangulasi sumber dan triangulasi metode.

\section{HASIL}

Komponen yang diteliti pada penelitian ini adalah komponen input, proses dan output. Komponen input terdiri dari kebijakan, tenaga pelaksana, pembiayaan, sarana dan prasarana. Komponen proses terdiri dari pemilahan, pengumpulan, pengangkutan, pengolahan akhir dan pengawasan. Komponen output yaitu kesesuaian konsep Green Hospital berdasarkan Kepmenkes RI Nomor 1204/MENKES/SK/X/2004 dan standar Green Hospital oleh Kementerian Kesehatan RI terhadap pelaksanaan sistem pengelolaan limbah medis padat di RSUP Dr. M. Djamil Padang.

\section{Komponen input}

Ditemukan bahwa RSUP Dr. M. Djamil Padang telah memiliki SOP pengelolaan limbah medis padat yang berdasarkan pada Keputusan Menteri Kesehatan Nomor 1204 Tahun 2004 tentang Persyaratan Kesehatan Lingkungan Rumah Sakit. Instalasi Kesehatan Lingkungan rumah sakit bertanggung jawab dalam pelaksanaan pengelolaan limbah medis padat.

Sumber dana yang digunakan dalam pengelolaan sampah medis berasal dari dana APBN (Anggaran Pendapatan dan Belanja Negara). Sebagian besar dana tersebut digunakan untuk pengolahan akhir limbah medis padat, dikarenakan pihak rumah sakit harus membayar sebanyak Rp. 20.000,-/kg sampah medis yang akan diolah oleh PT. Tenang Jaya Sejahtera.

Sarana dan prasarana yang dimiliki rumah sakit dalam pelaksanaan pengelolaan limbah medis padat diantaranya tempat sampah untuk limbah medis, Safety box atau menggunakan jerigen untuk limbah benda tajam, plastik pembungkus berwarna kuning untuk limbah medis dan farmasi, dan ungu untuk sitotoksik, APD berupa masker, handscoon, sepatu boots, dan baju kerja untuk petugas pengangkut sampah, troli pengangkut limbah medis, dan TPS untuk limbah medis. 
Sarana yang tidak dimiliki oleh rumah sakit yaitu jalur khusus dalam pengangkutan limbah medis padat. Ketersediaan dari sarana dan prasarana terkait pengelolaan limbah medis padat di rumah sakit dinilai mencukupi. TPS khusus limbah medis belum sesuai standar dari Kepmenkes RI Nomor 1204 Tahun 2004.
Berikut hasil wawancara mendalam dan telaah dokumen tentang kebijakan limbah medis padat yang dilakukan di RSUP Dr. M. Djamil Padang.

Tabel 1. Matriks triangulasi kebijakan

\begin{tabular}{lll}
\hline \multicolumn{1}{c}{ Wawancara Mendalam } & \multicolumn{1}{c}{ Telaah Dokumen } & \multicolumn{1}{c}{ Kesimpulan } \\
\hline RSUP Dr. M. Djamil Padang & RSUP Dr. M. Djamil Padang & RSUP Dr. M. Djamil Padang \\
memiliki SOP & memiliki SOP pengelolaan & memiliki SOP pengelolaan limbah \\
pengelolaanlimbah medis & limbah medis padat Rumah & medis padat \\
padat berdasarkan pada & Sakit yang diperbarui bulan & berdasarkan pada Kepmenkes No \\
Kepmenkes No 1204 tahun & April 2018. SOP berpedoman & 1204 tahun 2004 tentang Persyaratan \\
2004. Setiap tahunnya SOP & kepada Kepmenkes No 1204 & Kesehatan Lingkungan Rumah Sakit \\
akan diperbarui. & tahun 2004 &
\end{tabular}

\author{
Kebijakan terkait \\ pengelolaan limbah \\ medis padat disosialisasikan \\ oleh pihak kesling dan PPI \\ kepada seluruh pekerja yang \\ berhubungan langsung dengan \\ limbah \\ medis padat
}

Kebijakan telah

disosialisasikan kepada semua

tenaga medis atau pekerja di Rumah Sakit yang berhubungan langsung dengan limbah medis padat.
Berdasarkan tabel 1 diketahui bahwa RSUP Dr. M. Djamil Padang telah memilki SOP terkait pengelolaan limbah medis padat. SOP tersebut telah diperbaharui pada bulan APril 2018 dengan berpedoman kepada Kepmenkes No 1204 tahun 2004. Kebijakan terhadap pengelolaan limbah medis padat telah disosialisasikan oleh pihak kesling dan PPI kepada seluruh pekerja yang pekerjaannya berhubungan langsung dengan limbah medis padat. Berikut hasil wawancara mendalam dan telaah dokumen tentang tenaga pelaksana limbah medis padat yang dilakukan di RSUP Dr. M. Djamil Padang.

Tabel 2. Matriks Triangulasi Tenaga Pelaksana

\begin{tabular}{|c|c|c|}
\hline Wawancara Mendalam & Telaah Dokumen & Kesimpulan \\
\hline Tenaga pelaksana di Instalasi & Tenaga pelaksana di Instalasi & Instalasi Kesehatan \\
\hline Kesehatan & Kesehatan & Lingkungan RSUP Dr. \\
\hline Lingkungan RSUP Dr. M. Djamil & Lingkungan RSUP Dr. & M. Djamil Padang memiliki \\
\hline Padang berjumlah 11 orang & M. Djamil Padang telah & tenaga pelaksana sebanyak 11 \\
\hline & memiliki SK. & $\begin{array}{l}\text { orang. Pelatihan terkait tata } \\
\text { cara pengelolaan limbah B3 }\end{array}$ \\
\hline \multirow{8}{*}{$\begin{array}{l}\text { Tenaga pelaksana instalasi } \\
\text { Kesehatan Lingkungan dan } \\
\text { petugas cleaning service telah } \\
\text { mendapatkan pelatihan terkait } \\
\text { pengelolaan limbah B3 }\end{array}$} & & Rumah Sakit diberikan kepada \\
\hline & Tenaga pelaksana & kepala instalasi dan \\
\hline & instalasi kesehatan lingkungan & penanggung jawab instalasi \\
\hline & memiliki sertifikat pelatihan & dari Dinas Kesehatan. \\
\hline & mengenai tata cara & Petugas cleaning service \\
\hline & pengelolaan limbah B3 & berjumlah 8 orang. Jumlah \\
\hline & Rumah Sakit dari Dinas & . \\
\hline & Kesehatan. & mencukupi. \\
\hline
\end{tabular}

Petugas cleaning service pengangkutan limbah medis dan non medis berjumlah 8 orang. 
Berdasarkan tabel 2 didapatkan informasi bahwa terdapat 11 orang tenaga pelaksana di instalasi kesehatan lingkungan RSUP Dr. M. jamil Padang. Bagi tenaga cleaning service telah mendapatkan pelatihan terkait pengelolaan limbah
B3. Petugas tersebut berjumlah 8 orang dan boleh dikatan telah mencukupi.

Berikut hasil wawancara mendalam dan telaah dokumen tentang pembiayaan limbah medis padat yang dilakukan di RSUP Dr. M. Djamil Padang.

Tabel 3. Matriks Triangulasi Pembiayaan

\begin{tabular}{lll}
\hline \multicolumn{1}{c}{ Wawancara Mendalam } & \multicolumn{1}{c}{ Telaah Dokumen } & \multicolumn{1}{c}{ Kesimpulan } \\
\hline Sumber dana dalam pengelolaan & Terdapat rincian anggaran terkait & Sumber dana dalam \\
limbah medis berasal dari dana & pengelolaan limbah medis padat, & pengelolaan limbah \\
APBN. Dana yang disediakan & yaitu rincian pembiayaan & medis padat di Rumah \\
untuk pengelolaan limbah medis & pengangkutan dan pemusnahan & Sakit berasal dari dana \\
padat dinilai mencukupi. & limbah B3 oleh pihak ketiga. & APBN. Dana tersebut \\
& & sudah mencukupi. \\
\hline
\end{tabular}

Berdasarkan tabel 3 diketahui pembiayaan untuk pengelolaan limbah medis padat berasal dari dana APBN yang dinilai telah mencukupi. Terdapat rincian anggaran terkait pengelolaan tersebut. Berikut hasil wawancara mendalam dan telaah dokumen tentang sarana prasarana akhir limbah medis padat yang dilakukan di RSUP Dr. M. Djamil Padang.

Tabel 4. Matriks Triangulasi Sarana dan Prasarana

\begin{tabular}{|c|c|c|c|}
\hline $\begin{array}{l}\text { Wawancara } \\
\text { Mendalam }\end{array}$ & $\begin{array}{l}\text { Observasi } \\
\text { Lapangan }\end{array}$ & Telaah Dokumen & Kesimpulan \\
\hline $\begin{array}{l}\text { Prasarana dalam } \\
\text { pelaksanaan } \\
\text { pengelolaan limbah } \\
\text { medis padat sudah } \\
\text { mencukupi, namun } \\
\text { belum sesuai standar. }\end{array}$ & $\begin{array}{l}\text { Tersedianya tempat } \\
\text { limbah } \\
\text { terpisah antara limbah } \\
\text { medis dan non medis } \\
\text { padat di setiap ruangan } \\
\text { layanan kesehatan. }\end{array}$ & $\begin{array}{l}\text { - Ada Izin TPS } \\
\text { limbah B3 Rumah } \\
\text { Sakit } \\
\text { yang masih berlaku } \\
\text { - } \text { Ada Dokumen } \\
\text { Inventarisasi } \\
\text { fasilitas/ peralatan } \\
\text { pengelolaan limbah } \\
\text { medis }\end{array}$ & $\begin{array}{l}\text { Telah tersedia } \\
\text { prasarana yang } \\
\text { mencukupi, namun } \\
\text { sarana } \\
\text { masih belum memadai. }\end{array}$ \\
\hline
\end{tabular}

Berdasarkan tabel 4 diketahui sarana prasarana belum memadai sesuai dengan standar sehingga masih perlu dalam peningkatan dan

\section{Komponen proses}

RSUP Dr. M. Djamil Padang telah melakukan pemilahan sampah berdasarkan sifatnya. Pemilahan limbah medis padat dilakukan terhadap sampah infeksius, benda tajam, farmasi, dan sitotoksik pada setiap ruang penghasil limbah. Tempat sampah telah dibedakan antara tempat sampah medis dan non medis yang ditandai dengan warna kantong plastik dan warna tempat sampah. Warna kuning untuk tempat sampah infeksius dan farmasi, dan warna ungu untuk sampah sitotoksik. Namun masih ditemukan pencampuran antara sampah infeksius dengan non infeksius. Rumah sakit belum melakukan kegiatan minimisasi limbah medis padat pada sumber. Baik pada limbah non medis maupun limbah medis padat. Namun pihak kesehatan lingkungan telah membuat perencanaan terkait minimisasi limbah padat. Seperti melakukan reuse pada botol-botol kaca maupun botol infus dan recycle pada botol-botol minum. Proses selanjutnya adalah pengumpulan limbah medis padat oleh petugas kebersihan khusus pengumpul sampah. Pengumpulan dilakukan pada setiap ruangan penghasil limbah medis padat. Pengumpulan pemenuhan sarana prasaran agar sesuai dengan standar yang berlaku

limbah medis padat sudah menggunakan troli yang tertutup dan terpisah antara limbah medis dan non medis padat. Namun sampah medis dan non medis yang telah dikumpulkan hanya diletakkan di lantai bagian luar gedung rumah sakit sampai petugas pengangkut datang untuk mengangkut sampah ke TPS.

Selain itu juga tidak ada jalur khusus dalam pengumpulan sampah medis. Setelah pengumpulan, sampah diangkut menggunakan troli atau becak pengangkut sampah untuk dibawa ke TPS. Petugas yang melakukan pengumpulan dan pengangkutan dilengkapi dengan APD, diantaranya sarung tangan karet, sepatu safety boots, masker, pakaian dengan lengan dan kaki tertutup. Pengangkutan sampah ke TPS tidak menggunakan jalur khusus dan tidak dilakukan penimbangan sebelum sampah masuk ke TPS. Untuk pengangkutan limbah medis padat ke tempat pemusnahan, rumah sakit bekerjasama dengan pihak ketiga, yaitu PT. Tenang Jaya yang berlokasi di Karawang, Jawa Barat. Pihak ketiga datang 2-3 kali seminggu untuk mengambil sampah medis. Hal tersebut menyebabkan penumpukan sampah di TPS. Pemusnahan limbah 
medis padat menggunakan insinerator. Petugas pengolahan akhir limbah sudah menggunakan APD lengkap yang terdiri dari sarung tangan karet, masker, kacamata safety, pakaian khusus, sepatu safety boots, dan helm. Kondisi dari tempat pemusnahan adalah bersih, lantai tidak licin dan mesin dari insinerator tidak menimbulkan bising dan tidak menimbulkan polusi udara.

Pihak Kesehatan Lingkungan dan tim PPI rumah telah melakukan pengawasan rumah sakit terkait pengelolaan limbah medis padat, mulai dari pemilahan, pengumpulan, pengangkutan, dan pemusnahan akhir limbah. Pengawasan terhadap proses pemilahan, pengumpulan dan pengangkutan dilakukan setiap hari. Pengawasan terhadap proses pemusnahan akhir limbah dilakukan 1-2 kali setiap tahun, yaitu dengan cara melakukan kunjungan dari pihak rumah sakit ketempat pengolahan akhir limbah medis padat yang berlokasi di Karawang, Jawa Barat. Berikut hasil wawancara mendalam dan telaah dokumen tentang pemilahan akhir limbah medis padat yang dilakukan di RSUP Dr. M.Djamil Padang

Tabel 5. Matriks Triangulasi Pemilahan

\begin{tabular}{lll}
\hline \multicolumn{1}{c}{ Wawancara Mendalam } & \multicolumn{1}{c}{ Observasi Lapangan } & \multicolumn{1}{c}{ Kesimpulan } \\
\hline Pemilahan limbah medis & Pemilahan sudah dilakukan di & Pemilahan sudah \\
padat sudah dilakukan & setiap ruangan yaitu dengan & dilakukan berdasarkan \\
terhadap limbah infeksius, & membedakan & sifat dan jenis limbah. \\
benda tajam, farmasi, dan & Tempat berdasarkan & Pada poliklinik, bagian \\
sitotoksik pada setiap ruang & sifatnya. Pemilahan limbah & farmasi dan instalasi \\
penghasil limbah. Setiap & terdiri dari limbah infeksius, & rawat inap terdapat \\
tempat limbah diberi label dan & benda tajam, sitotoksik, & pemilahan tempat limbah \\
warna yang berbeda sesuai & farmasi, dan non infeksius. & infeksius dan benda tajam. \\
sifatnya. & & Pada ruang kemoterapi \\
& & dan radiologi terdapat \\
& & tempat limbah infeksius \\
& & dan sitotoksik.
\end{tabular}

\footnotetext{
Masalah yang ditemukan pada saat pemilahan limbah medis padat adalah terjadi kesalahan dalam pemilahan, baik kesalahan dari perawat, dokter, hingga keluarga pasien
}

Pemilahan sampah medis padat telah itu pasien, tenaga medis, maupun keluarga pasien. dilakukan terhadap semua jenis limbah dan setiap Berikut adalah hasil wawancara mendalam dan wadah limbah telah diberi label dan warna berbeda sesuai dengan jenis limbah. Namun masih terdapat kesalahan dalam pemilahan oleh beberapa pihak baik telaah dokumen tentang pengumpulan limbah medis padat di RSUP Dr. M.Djamil Padang.

Tabel 6. Matriks Triangulasi Pengumpulan

\begin{tabular}{|c|c|c|}
\hline Wawancara Mendalam & Observasi Lapangan & Kesimpulan \\
\hline $\begin{array}{l}\text { Limbah medis padat diangkut } \\
\text { dari setiap ruangan penghasil } \\
\text { limbah oleh petugas CS khusus } \\
\text { pengumpul limbah. Limbah } \\
\text { medis yang telah dikumpulkan } \\
\text { dari setiap ruangan diletakkan di } \\
\text { lantai bagian luar gedung Rumah } \\
\text { Sakit sampai petugas pengangkut } \\
\text { datang untuk mengangkut limbah } \\
\text { keTPS. } \\
\text { Pengumpulan limbah medis } \\
\text { padat dilakukan oleh petugas CS } \\
\text { yang bertugas pada masing- } \\
\text { masing ruangan. }\end{array}$ & $\begin{array}{l}\text { Pengumpulan dilakukan } \\
\text { oleh petugas CS yang bertugas } \\
\text { pada masing- masing ruangan. } \\
\text { Pengumpulan menggunakan } \\
\text { troli yang tertutup dan terpisah } \\
\text { antara limbah medis dan non } \\
\text { medis. } \\
\text { Limbah yang telah dikumpulkan } \\
\text { hanya diletakkan di lantai bagian } \\
\text { luar gedung Rumah Sakit. }\end{array}$ & $\begin{array}{l}\text { Pengumpulan dilakukan oleh } \\
\text { petugas CS yang bertugas pada } \\
\text { masing- masing ruangan. } \\
\text { Pengumpulan dilakukan jika } \\
\text { tempat limbah sudah } 2 / 3 \\
\text { penuh. Lalu limbah yang telah } \\
\text { terkumpul dari setiap ruangan } \\
\text { diletakkan di lantai bagian luar } \\
\text { gedung Rumah Sakit dan } \\
\text { selanjutnya diangkut oleh CS } \\
\text { pengangkut ke TPS limbah } \\
\text { medis. }\end{array}$ \\
\hline
\end{tabular}

Pengumpulan limbah medis dibawa dari setiap ruangan penghasil limbah oleh petugas CS khusus pengumpul limbah. Limbah medis yang telah dikumpulkan diletakkan di bagian luar gudeng Rumah Sakit sampai akhirnya diangkut oleh petugas untuk dibawa ke TPS. Pengumpulan menggunakan troli yang tertutup dan sudah terpisah antara limbah medis dengan limbah non medis. Pengumpulan tersebut dilakukan setelah tempat limbah 2/3 terpenuhi. Berikut ini disajikan hasil wawancara mendalam dan telaah dokumen terkait pengangkutan limbah medis padat di RSUP Dr. M. Djamil Padang 
Tabel 7. Matriks Triangulasi Pengangkutan

\begin{tabular}{|c|c|c|c|}
\hline $\begin{array}{l}\text { Wawancara } \\
\text { Mendalam }\end{array}$ & Observasi Lapangan & Telaah Dokumen & Kesimpulan \\
\hline $\begin{array}{l}\text { Pengangkutan on } \\
\text { site menggunakan } \\
\text { troli/sulo yang } \\
\text { tertutup dilakukan oleh } \\
\text { petugas CS khusus } \\
\text { pengangkut limbah, lalu } \\
\text { dibawa ke TPS. } \\
\text { Pengangkutan off site } \\
\text { menggunakan truk } \\
\text { berkontainer yang } \\
\text { terdapat simbol } \\
\text { bahaya/infeksius } \\
\text { pada truk. }\end{array}$ & $\begin{array}{l}\text { Pengangkutan limbah } \\
\text { medis padat menggunakan } \\
\text { alat angkut/troli } \\
\text { terpisah dengan limbah } \\
\text { non medis padat dan } \\
\text { Pengangkutan off site } \\
\text { menggunakan truk } \\
\text { pengangkut khusus limbah } \\
\text { medis yang tertutup dan } \\
\text { terdapatsimbol } \\
\text { bahaya pada kontainer. }\end{array}$ & $\begin{array}{l}\text { - Ada MoU dengan } \\
\text { pengolah limbah dan } \\
\text { atau } \\
\text { transporter yang } \\
\text { memiliki ijin dari } \\
\text { KLHK } \\
\text { - } \\
\text { Ada manifest limbah B3 }\end{array}$ & $\begin{array}{l}\text { Pengangkutan on site } \\
\text { menggunakan troli/sulo } \\
\text { yang } \\
\text { tertutup dan } \\
\text { terpisah antara limbah } \\
\text { medis dan non medis. } \\
\text { Pengangkutan off site } \\
\text { menggunakan truk yang } \\
\text { memiliki simbol bahaya } \\
\text { pada kontainer truk. } \\
\text { Petugas pengangkutan } \\
\text { onsite belum } \\
\text { menggunakan APD } \\
\text { lengkap, namun petugas } \\
\text { pengangkutan off site } \\
\text { sudah } \\
\text { menggunakan APD } \\
\text { lengkap. }\end{array}$ \\
\hline
\end{tabular}

Petugas yang melakukan pengangkutan keTPS diberi APD lengkap, namun masih ada yang tidak menggunakan APD lengkap
Petugas pengangkutan on site masih ada yang tidak menggunakan masker. Petugas pengangkut Off site menggunakan lengkap.lengkapll
Pengangkutan on site dilakukan menggunakan troli oleh petugas CS khusus pengangkut limbah dan dibawa ke TPS. Sementara itu pengangkutan off site menggunakan truk berkontainer yang terdapat simbol bahaya/ infeksius pada truk. Petugas pengangkut sampah dalam melakukan tugasnya menggunakan
APD lengkap, namun masih ada yang tidak menggunakan APD lengkap. Berikut ulasan hasil wawancara mendalam dan telaah dokumen mengenai pegelolaan akhir limbah medis padat yang dilakukan di RSUP Dr. M.Djamil Padang.

Tabel 8. Matriks Triangulasi Pengolahan Akhir

\begin{tabular}{|c|c|c|}
\hline Wawancara Mendalam & Telaah Dokumen & Kesimpulan \\
\hline $\begin{array}{l}\text { RSUP Dr. M. Djamil bekerjasama } \\
\text { dengan PT. Tenang Jaya Sejahtera } \\
\text { untuk pengolahan akhir. Pihak } \\
\text { tersebut telah mempunyai izin } \\
\text { operasional dari KLH. }\end{array}$ & $\begin{array}{l}\text { RSUP Dr. M. Djamil } \\
\text { memiliki MoU dengan } \\
\text { pengolah limbah yang } \\
\text { memiliki ijin dari KLH. }\end{array}$ & $\begin{array}{l}\text { RSUP Dr. M. Djamil } \\
\text { bekerjasama dengan } \\
\text { PT. Tenang Jaya } \\
\text { Sejahtera untuk } \\
\text { pengolahan akhir. } \\
\text { Pengolahan akhir } \\
\text { menggunakan }\end{array}$ \\
\hline $\begin{array}{l}\text { Sebelum dimusnahkan } \\
\text { menggunakan insinerator, limbah } \\
\text { ditimbang terlebih dahulu oleh } \\
\text { pihak pemusnah Petugas } \\
\text { pengolahan akhir sudah } \\
\text { menggunakan APD lengkap. } \\
\text { Kondisi dari tempat pemusnahan } \\
\text { adalah bersih, lantai tidak licin dan } \\
\text { mesin dari insinerator tidak } \\
\text { menimbulkan bising dan tidak } \\
\text { menimbulkan polusi } \\
\text { udara }\end{array}$ & $\begin{array}{l}\text { Berupa foto dokumentasi } \\
\text { kunjungan pihak Rumah } \\
\text { Sakit ke tempat pengolahan } \\
\text { akhir (PT. Tenang Jaya } \\
\text { Sejahtera) terlihat proses } \\
\text { Pengolahan akhir } \\
\text { menggunakan insinerator } \\
\text { dan petugas pengolahan akhir } \\
\text { menggunakan APD lengkap. }\end{array}$ & $\begin{array}{l}\text { insinerator. Kondisi } \\
\text { tempat pengolahan } \\
\text { akhir bebas dari polusi } \\
\text { suara dan udara. }\end{array}$ \\
\hline
\end{tabular}

Pengolahan akhir limbah medis padat bekerjasama dengan PT Tenang Jaya Sejahtera yang telah mendapatkan izin dari KLH. Sebelum dimusnahkan maka dilakukan penimbangan terlebih dahulu terhadap limbah tersebut. Semua petugas menggunakan APD lengkap dan kondisi tempat pemusnahan bersih, tidak licin, dan mesin insinerator tidak menimbulkan bising serta tidak menimbulkan polusi udara. Berikut didapatkan hasil dari wawancara mendalam dan telaah dokumen terhadap pengawasan limbah medis padat yang dilakukan di RSUP Dr. M.Djamil Padang. 
Tabel 9. Matriks Triangulasi Pengawasan

\begin{tabular}{|c|c|c|}
\hline Wawancara Mendalam & Telaah Dokumen & Kesimpulan \\
\hline $\begin{array}{l}\text { Telah dilakukan pengawasan oleh } \\
\text { pihak Kesehatan Lingkungan } \\
\text { Rumah Sakit terkait pengelolaan } \\
\text { limbah medis padat, mulai dari } \\
\text { pemilahan, pengumpulan, } \\
\text { pengangkutan, dan pemusnahan } \\
\text { akhir limbah. }\end{array}$ & $\begin{array}{l}\text { Terdapat foto kunjungan pihak } \\
\text { Rumah Sakit ke tempat } \\
\text { pengolahan akhir limbah. }\end{array}$ & $\begin{array}{l}\text { Pengawasan dilakukan } \\
\text { oleh Instalasi } \\
\text { Kesehatan Lingkungan dan } \\
\text { Instalasi PPI } \\
\text { terhadap proses } \\
\text { pengelolaan limbah } \\
\text { medis padat. Pengawasan } \\
\text { terhadap pemilahan, } \\
\text { pengumpulan, } \\
\text { pengangkutan dilakukan } \\
\text { setiap hari. Pengawasan } \\
\text { terhadap proses } \\
\text { pengolahan akhir }\end{array}$ \\
\hline $\begin{array}{l}\text { Pengawasan tersebut menjadikan } \\
\text { petugas CS menjadi lebih disiplin } \\
\text { dalam menggunakan APD dan } \\
\text { jarang terjadi kesalahan dalam }\end{array}$ & & $\begin{array}{l}\text { limbah berupa } \\
\text { kunjungan pihak Rumah } \\
\text { Sakit ke PT. Tenang Jaya } \\
\text { Sejahtera. }\end{array}$ \\
\hline
\end{tabular}
sumbernya.

Pengawasan dilakukan oleh pihak Kesehatan Lingkungan RS mulai dari proses pemilahan sampai dengan pemusnahan akhir limbah. Pengawasan tersebut menjadikan petugas CS menjadi lebih disiplin dalam penggunaaan APD sehingga jarang terjadi kesalahan dalam pemilahan limbah medis padat pada sumbernya. Komponen output

Berdasarkan hasil wawancara yang dilakukan kepada informan, didapatkan hasil bahwa RSUP Dr. M. Djamil Padang belum memiliki perencanaan terkait kebijakan, program kerja dan pengorganisasian terkait konsep Green Hospital. Hal tersebut dikarenakan tidak adanya usulan dari direktur Rumah Sakit untuk membentuk kebijakan tertulis mengenai Green Hospital. Berikut hasil wawancara mendalam dengan informan:

"Belum ada perencanaan dalam membuat konsep green hospital. Dulu pernah dibahas tentang green hospital ini, sekitar tahun 2016. Tapi kebijakan tertulisnya belum ada. Rumah Sakit hanya berfokus kepada bagaimana upaya atau langkah konkrit dalam mencapai green hospital tersebut." (Inf-1)

\begin{abstract}
"Visi misi terkait Green Hospital belum ada, sejauh perencanaan untuk buat kebijakan tersebut juga belum ada. Karena memang dari atas belum ada rencana dalam membuat kebijakan tentang green hospital." (Inf-2) "Rumah Sakit belum ada kebijakan tentang green hospital. Alasannya kurang tau, soalnya yang mengusulkan untuk buat kebijakan kan direktur dan itu tanggung jawab SDM dalam buat kebijakan." (Inf3). Berikut ini adalah data hasil wawancara mendalam dan telaah dokumen mengenai perwujudan konsep Green Hospital medis padat yang dilakukan di RSUP Dr. M.Djamil Padang.

RSUP Dr. M. Djamil Padang belum memilki perencanaan dalam kebijakan, program kerja serta pengorganisasian terkait konsep Green Hospital tersebut. Namun pelaksanaan yang telah dilakukan oleh Rumah Sakit dalam mewujudkan konsep Green Hospital diantaranya telah memiliki SOP pengelolaan limbah medis padat berdasarkan Kepmenkes RI No. 1204 th 2004 serta telah terlaksana pemilahan limbah dan pemberian warna berdasarkan sifatnya.
\end{abstract}

Tabel 10. Matriks Triangulasi Perwujudan Konsep Green Hospital

\begin{tabular}{lll}
\hline \multicolumn{1}{c}{ Wawancara Mendalam } & \multicolumn{1}{c}{ Telaah Dokumen } & Kesimpulan \\
\hline RSUP Dr. M. Djamil Padang belum & Rumah Sakit tidak memiliki visi & RSUP Dr. M. Djamil \\
memiliki perencanaan dalam & dan misi terkait Green Hospital, & Padang belum memiliki \\
kebijakan, program kerja dan & SK Tim Green Hospital dan SK & perencanaan tertulis terkait \\
pengorganisasian terkait konsep & Kebijakan Penerapan Green & kreen Hospital karena \\
masih kurangnya sosialisasi & terkait Green Hospital. Namun \\
& Hospital. & Rumah Sakit telah berupaya \\
& & untuk mewujudkan Green \\
& & Hospital. \\
& & \\
Pelaksanaan yang telah dilakukan & & \\
Rumah Sakit dalam mewujudkan & & \\
konsep Green Hospital diantaranya & & \\
Rumah Sakit telah memiliki SOP & & \\
pengelolaan limbah medis padat & & \\
berdasarkan Kepmenkes RI No. 1204 & & \\
Tahun 2004, telah terlaksana & & \\
pemilahan limbah dan pemberian & & \\
warna berdasarkan sifatnya. & & \\
\hline
\end{tabular}




\section{PEMBAHASAN}

Kebijakan tentang pengelolaan limbah medis padat berupa SOP telah disosialisasikan kepada seluruh pekerja yang ada di RSUP Dr. M. Djamil Padang yang berkaitan langsung dengan limbah medis padat. Sosialisasi sangat diperlukan agar kegiatan pengelolaan limbah medis padat terlaksana dengan baik dan berkelanjutan. Dalam upaya mengurangi timbulnya risiko terjadinya gangguan kesehatan baik bagi pekerja Rumah Sakit, masyarakat sekitar Rumah Sakit, maupun lingkungan. Pada penelitian yang dilakukan oleh A.T Lando et al tahun 2017 di RS Gowa Syekh Yusuf bahwa belum tersedianya SOP yang mendukung dalam minimisasi sampah medis dan skema dalam pengelolaan sampah padat RS Gowa Syekh Yusuf tidak sesuai dengan peraturan kemenkes RI No.1204/Menkes/SK/X/2004. (Lando et al,,2017)

Sumber daya manusia merupakan unsur penting dalam penyelenggaraan suatu organisasi agar bisa tetap bertahan di masa yang akan datang. Pada pengelolaan limbah medis ini ketersediaan tenaga pengelola yang memiliki kualifikasi dan pengalaman sangat diperlukan untuk terlaksananya kegiatan pengelolaan limbah medis padat. (Adisasmito, 2014)

Setiap pekerja yang berkaitan langsung dengan limbah medis padat di RSUP Dr. M. Djamil telah mendapatkan pelatihan dari pihak Kesehatan Lingkungan dan PPI mengenai tata cara pengelolaan limbah medis padat yang baik dan benar. Kegiatan ini bertujuan untuk mengedukasi pekerja bahwa dalam penanganan limbah medis padat harus sesuai dengan standar dan diikuti dengan langkah-langkah yang benar.

Berdasarkan Kepmenkes RI Nomor 1204 Tahun 2004 tentang Persyaratan Kesehatan Lingkungan Rumah Sakit, pengelolaan limbah di rumah sakit dilakukan oleh tenaga sanitasi. Penanggung jawab kesehatan lingkungan di rumah sakit kelas A dan B adalah seorang tenaga yang memiliki kualifikasi sanitarian serendah-rendahnya berijazah sarjana (S1) di bidang kesehatan lingkungan, teknik lingkungan, biologi, teknik kimia, dan teknik sipil. Tenaga kesehatan diusahakan mengikuti pelatihan khusus di bidang kesehatan lingkungan rumah sakit yang diselenggarakan oleh pemerintah atau pihak lain terkait, sesuai dengan peraturan perundangan yang berlaku.

Sumber dana dalam pengelolaan limbah medis padat di RSUP Dr. M. Djamil Padang berasal dari dana APBN. Hal ini sejalan dengan penelitian Sari di RSUD Lubuk Sikaping tahun 2016 bahwa anggaran untuk kegiatan pengelolaan limbah medis padat ini berasal dari dana BLUD Rumah Sakit. Dana dalam pengelolaan limbah medis padat digunakan untuk perawatan, pemeliharaan dan perbaikan sarana dan prasarana (Sari, 2016).

Sarana prasarana yang dimiliki Rumah Sakit dalam pelaksanaan pengelolaan limbah medis padat diantaranya tempat limbah untuk limbah medis, Safety box dan jerigen untuk limbah benda tajam, plastik pembungkus berwarna kuning untuk limbah medis dan farmasi, dan ungu untuk sitotoksik, APD berupa masker, handscoon, sepatu boots, dan baju kerja untuk petugas pengangkut limbah, troli pengangkut limbah medis dan TPS limbah medis.

Dalam pengelolan limbah medis padat rumah sakit, penyediaan sarana dan prasarana harus sesuai dengan yang dipersyaratkan pada Kepmenkes RI No. 1204 Tahun 2004. Pada hasil penelitian Febrina di Rumah Sakit X Jakarta ditemukan bahwa sarana dan prasarana yang disediakan oleh pihak Rumah Sakit sudah cukup yaitu tempat limbah dan kantong plastik khusus limbah medis dan non medis, gerobak untuk mengangkut limbah, APD utuk petugas CS, TPS hingga insinerator untuk pemusnahan limbah medis padat (Febrina, 2011).

Pemilahan limbah sudah dilakukan oleh RSUP Dr. M. Djamil Padang dengan baik dan sesuai jenis limbah yang dihasilkan, diantaranya pemilahan limbah infeksius, non infeksius, benda tajam, dan sitotoksik. Penelitian Mayonetta di Puskesmas Kabupaten Sidoarjo tahun 2016, pemilahan limbah dilakukan berdasarkan jenis limbah yaitu infeksius, benda tajam, farmasi dan botol infus bekas. Pemilahan dilakukan dengan menyediakan kemasan yang berbeda bagi setiap jenis limbah. Puskesmas memberikan label "limbah medis" pada wadah limbah infeksius benda tajam dan farmasi (Mayonetta, 2016).

Penelitian yang dilakukan oleh Pratiwi dan Maharani tahun 2013 terhadap pada puskemas Kabupaten Pati bahwa pemilahan sampah medis diberikan label dan dalam keadaan tertutup sedangkan untuk sampa non medis tidak diberi label dan dibiarkan terbuka (Pratiwi dan Maharani, 2013).

Pemilahan dilakukan tidak hanya untuk mengurangi biaya pengolahan limbah medis, namun juga mampu mencegah terkontaminasinya limbah umum oleh limbah infeksius yang berpotensi memberikan penyakit menular bagi pekerja yang menangani limbah umum. Selain itu mewujudkan pelaksanaan minimisasi limbah medis padat pada sumber dapat mengurangi timbulan limbah yang dihasilkan Rumah Sakit. Limbah dari setiap ruangan yang telah dikumpulkan dibiarkan terletak di lantai. Limbah yang dibiarkan terletak di lantai rumah sakit dapat menimbulkan masalah, seperti kurangnya estetika, menimbulkan bau, dan meninggalkan bekas licit dari limbah. Hal tersebut dapat mempengaruhi kenyamanan pengunjung Rumah Sakit.

Berdasarkan Keputusan Menteri Kesehatan RI nomor 1204 tahun 2004, pengumpulan limbah medis padat dari setiap ruangan penghasil limbah harus menggunakan troli khusus yang tertutup. Troli pengangkut limbah harus dibersihkan setiap hari dengan desinfektan. Kantong yang akan diangkut dapat disegel dengan membuat simpul ikatan. Kontainer benda tajam dimasukkan dalam kantong kuning sebelum diangkut dari bangsal Rumah Sakit. Pengangkutan limbah menggunakan troli yang terpisah antara limbah medis dan non medis padat. Untuk pengangkutan limbah medis padat ke tempat 
pemusnahan, Rumah Sakit bekerjasama dengan pihak ketiga, yaitu PT. Tenang Jaya yang berlokasi di Karawang, Jawa Barat.

Adapun syarat pengangkutan limbah meninggalkan TPS Rumah Sakit yaitu (1) Kantong limbah medis padat sebelum dimasukkan ke kendaraan pengangkut harus diletakkan dalam kontainer yang kuat dan tertutup atau dapat langsung ditempatkan dalam kendaraan pengangkut; (2) Petugas yang menangani limbah medis, harus menggunakan APD yang terdiri dari: topi atau helm, masker, pelindung mata, pakaian panjang, apron untuk industri, pelindung kaki atau sepatu boot dan sarung tangan khusus; (3) Pengangkutan harus disertai dengan formulir atau manifest serah terima limbah medis; (4) Menggunakan kendaraan khusus pengangkut limbah infeksius yang tertutup dan terdapat simbol bahaya atau simbol limbah infeksius di bagian luar kendaraan atau kontainer (Kepmenkes, 2004).

Berdasarkan Kepmenkes nomor 1204 tahun 2004, Rumah Sakit yang tidak memiliki insenerator maka limbah medis padatnya harus dimusnahkan melalui kerjasama dengan pihak ketiga dan melakukan pemusnahan paling lama sekali dalam 24 jam apabila disimpan pada suhu ruang. Tetapi, setelah dilakukan observasi lapangan, ditemukan adanya penumpukan limbah medis padat di TPS. Hal tersebut dikarenakan Rumah Sakit menghasilkan limbah medis $\pm 400 \mathrm{~kg}$ setiap harinya, sedangkan pihak pengangkut hanya datang 2 kali dalam seminggu. RSUP M. Djamil sendiri masih menggunakan pihak ketiga dalam pemusnahan limbah semntara pada penelitian yang dilakukan oleh Leonita dan Yulianto tahun 2014 di Puskemas se Kota Pekanbaru bahwa terdapat 4 puskesmas yang melakukan pemusnahan sampah sendiri menggunakan insenerator dan terdapat 16 puskesmas yang masih melakukan pemusnahan ditempat lain. (Leonita dan Yulianto, 2014)

Pemusnahan limbah medis padat dapat dilakukan dengan menggunakan insinerator. Alat ini adalah sarana yang tepat untuk pemusnahan limbah medis karena limbah akan musnah baik benda tajam seperti jarum hingga kaca. Pemusnahan limbah semakin baik jika suhu insinerator yang digunakan di atas $1000^{\circ} \mathrm{C}$.

Pengawasan oleh Instalasi Kesehatan Lingkungan dan PPI Rumah Sakit dilakukan terhadap proses pemilahan, pengumpulan, pengangkutan, dan pemusnahan akhir limbah. Berdasarkan Kepmenkes nomor 1204 tahun 2004, bahwa pengawasan harus: (1) dilakukan oleh petugas sanitasi atau petugas penanggung jawab kesehatan lingkungan Rumah Sakit. (2) dilakukan pada setiap langkah-langkah pengelolaan limbah medis padat Rumah Sakit. (3) debu hasil pengolahan insenerator dilakukan sebelum dilakukan penimbunan di landfill. (4) Mengawasi pemakaian APD pada petugas kebersihan saat melakukan proses pengelolaan limbah medis padat.

Pengawasan yang dilakukan dinilai dapat mengurangi terjadinya kesalahan dalam pemilahan limbah medis dan non medis padat pada sumbernya. Selain itu dapat meningkatkan kedisiplinan petugas kebersihan dalam menggunakan APD saat mengangkut limbah.

Adapun kriteria Green Hospital dalam pengelolaan limbah padat berdasarkan Kementerian Kesehatan RI yaitu memiliki SOP pengelolaan limbah padat, memiliki logbook limbah B3, Neraca limbah B3, Manifest Limbah B3, TPS memenuhi syarat (sesuai dengan Kepmenkes RI nomor 1204 tahun 2004), memiliki insinerator sendiri atau bekerjasama dengan pihak ketiga dalam pemusnahan limbah medis padat, dan melakukan upaya minimisasi atau daur ulang limbah domestik atau non B3. (Kemenkes, 2016)

Salah satu Rumah Sakit yang sudah berupaya dalam mencapai konsep Green Hospital adalah Rumah Sakit Gaya Medistra yang berlokasi di Jakarta. Dalam pengelolaan limbah medis padat, Rumah Sakit Gaya Medistra Mulai telah melakukan pemisahan jenis limbah, menyediakan ruang penampungan limbah, hingga bekerjasama dengan pihak ketiga dalam hal pemusnahaan limbah. Selain itu pihak Rumah Sakit telah melakukan penimbangan pada limbah dan juga pengawasan, baik di lingkungan Rumah Sakit maupun tempat pengolahan akhir. (Go Green Hospital Gaya Medistra, 2018)

Upaya pelaksanaan pengelolaan limbah medis padat untuk mewujudkan konsep Green Hospital, maka pihak Rumah Sakit perlu melakukan pencatatan log book dan neraca limbah. Banyaknya limbah yang dihasilkan juga dapat menjadi bahan evaluasi dalam minimisasi limbah pada sumbernya. Selain itu hal yang perlu diperbaiki oleh Rumah Sakit adalah membuat TPS limbah medis padat yang layak dan sesuai standar. TPS yang terbuka dapat menimbulkan pencemaran dan berpotensi untuk dimasuki vektor penyakit.

\section{SIMPULAN}

RSUP Dr. M. Djamil Padang memiliki kebijakan berupa SOP terkait pengelolaan limbah medis padat, anggaran dan jumlah tenaga pelaksana mencukupi, semua sarana prasarana sesuai dengan standar kecuali TPS limbah medis padat. Pemilahan limbah dilakukan berdasarkan sifatnya. Pengangkutan limbah medis padat telah menggunakan troli tertutup. Pemusnahan menggunakan insinerator bekerjasama dengan pihak ketiga. Rumah sakit telah berupaya dalam mewujudkan Green Hospital melalui pelaksanaan pengelolaan limbah medis padat yang sesuai dengan Kepmenkes Nomor 1204 Tahun 2004. Untuk mencapai Green Hospital rumah sakit dapat memperbaiki sarana dan prasarana yang belum memadai dan menerapkan upaya minimisasi limbah medis dan non medis padat.

\section{UCAPAN TERIMA KASIH}

Ucapan terimakasih disampaikan kepada semua pihak yang telah terlibat dalam penelitian ini khususnya RSUP Dr. M. Djamil Padang Instalasi Kesehatan Lingkungan. 


\section{DAFTAR PUSTAKA}

Adisasmito W.2014, Sistem Manajemen Lingkungan Rumah Sakit, Jakarta: Rajawali Pers.

A.T Lando dan S.H Aly et al.2017, Evaluation Study of Medical Solid Waste Management in Syekh Yusuf Gowa Hospital. International Journal of Engineering and Science Application.Vol.4 N.2.

Azmal M, Kalhor R, Dehcheshmeh NF, Goharinezhad S, Heidari ZA, Farzianpour F, 2014, Going toward Green Hospital by Sustainable Healthcare Waste Management: Segregation, Treatment and Safe Disposal. Vol. 6 N.26 tahun 2014 32-40

Capai Go Green Hospital Gaya Medistra 2016 [cited 2018July].Availablefrom:http://www.medistra. com/index.php?option=com_content\&view $=$ art icle \&id $=255$

Febrina R, 2011, Sistem Pengelolaan Sampah Padat di Rumah Sakit X Jakarta. Universitas Indonesia. .

Kementerian Kesehatan Republik, 2016,Indonesia. Lomba Program Green Hospital Tingkat Pratama..Availablefrom:http://www.depkes.go .id/article/view/16102100001/Lomba-Green Hospital- bagi-Rumah-Sakit.html.
Keputusan Menteri Republik Indonesia No.1204/MENKES/SK/X/2004 tentang Persyaratan Kesehatan Lingkungan.

Leonita dan Yulianto, 2014, Pengelolaan limbah medis padat puskesmas se Kota Pekanbaru. Jurnal Kesehatan Komunitas. Vol. 2 N.4.

Mayonetta G, Warmadewanthi, 2016, Evaluasi Pengelolaan Limbah Padat B3 di Puskesmas Kabupaten Sidoarjo. Teknik Lingkungan Institut Teknologi Sepuluh Nopember.Vol. 5 N.2.

Pratiwi dan Maharani, 2013, Pengelolaan Limbah Medis Padat pada Puskesmas Kabupaten Pati. Jurnal Kesehatan Masuyarakat Unnes Semarang. Vol. 9 N.1 tahun 2013 74-78.

Putri CF, Purnomo D, Astuti E, 2016, Analisis Kesiapan Rumah Sakit Menuju Ramah Lingkungan (Green Hospital) di Kota Malang. Teknologi Industri. Vol.1(No Book-1 (2016): Prosiding SENIATI 2016).

Risnawati F, Purwanto, Setiani O,2015, Penerapan Green Hospital Sebagai Upaya Manajemen Lingkungan di Rumah Sakit Pertamina Cirebon. Vol.1. N.7 tahun 2015 26- 39.

Sari OI, 2016, Analisis Pengelolaan Sampah Medis Padat RSUD Lubuk Sikaping Kabupaten Pasaman. Universitas Andalas. 